\title{
Antitumor activity of bevacizumab in combination with capecitabine and oxaliplatin in human colorectal cancer xenograft models
}

\author{
MIEKO YANAGISAWA, KAORI FUJIMOTO-OUCHI, KEIGO YOROZU, \\ YORIKO YAMASHITA and KAZUSHIGE MORI
}

Product Research Department, Chugai Pharmaceutical Co., Ltd., 200 Kajiwara, Kamakura, Kanagawa 247-8530, Japan

Received February 20, 2009; Accepted March 30, 2009

DOI: $10.3892 /$ or_00000430

\begin{abstract}
To understand the mechanisms of the effects of combination treatments, we established animal models showing antitumor activity of bevacizumab as a monotherapy and in combination with capecitabine or capecitabine and oxaliplatin and measured thymidine phosphorylase (TP) and vascular endothelial growth factor (VEGF) levels. Tumorinoculated nude mice were treated with bevacizumab, capecitabine, and oxaliplatin, alone or in combination, after tumor growth was confirmed and volume and microvessel density (MVD) in tumors were evaluated. Levels of TP and VEGF in the tumor were examined by ELISA. Bevacizumab showed significant antitumor activity as a monotherapy in three xenograft models (COL-16-JCK, COLO 205 and CXF280). The MVD in tumor tissues treated with bevacizumab was lower than that of the control. Antitumor activity of bevacizumab in combination with capecitabine was significantly higher than that of each agent alone (COL16-JCK, COLO 205). Furthermore, the antitumor activity of bevacizumab in combination with capecitabine + oxaliplatin was significantly superior to that of capecitabine + oxaliplatin (COL-16-JCK). TP and VEGF levels were not increased by bevacizumab or capecitabine, respectively, suggesting there are other potentially efficacious mechanisms involved. In the present study we established human colorectal cancer xenograft models which reflect the efficacy of clinical combination therapies, capecitabine + bevacizumab and capecitabine + oxaliplatin + bevacizumab. We will further investigate the mechanisms of the combination therapies using these models.
\end{abstract}

Correspondence to: Mieko Yanagisawa, Product Research Department, Chugai Pharmaceutical Co., Ltd., 200 Kajiwara, Kamakura, Kanagawa 247-8530, Japan

E-mail: yanagisawamek@chugai-pharm.co.jp

Key words: bevacizumab, capecitabine, oxaliplatin, colorectal cancer, xenograft models, combination therapy, antitumor activity

\section{Introduction}

Bevacizumab (Avastin ${ }^{\circledR}$ ) is a genetically engineered humanized monoclonal antibody derived from murine anti-human vascular endothelial growth factor (VEGF) monoclonal antibody A4.6.1 $(1,2)$. It binds specifically to human VEGF, thereby blocking the binding of VEGF to VEGF receptors expressed on vascular endothelial cells. By blocking the biological activity of VEGF (3), bevacizumab or its murine equivalent A4.6.1 inhibits neovascularization in tumor tissues and thus suppresses tumor growth $(1,4,5)$. Clinically, it has been reported that bevacizumab significantly improved the survival benefit among patients with metastatic colorectal cancers in combination with irinotecan hydrochloride, fluorouracil, and leucovorin (IFL) and with fluorouracil and leucovorin (5FU/LV) (6,7). Capecitabine ( $\mathrm{N}^{4}$-pentyloxycarbonyl-5'-deoxy5-fluorocytidine, Xeloda $\left.^{\circledR}\right)$ is an oral fluoropyrimidine drug widely used and is enzymatically metabolized to 5-FU by thymidine phosphorylase (TP) highly expressed in tumors. It has been reported that the antitumor activity of capecitabine correlates with tumor levels of TP activity in xenograft models (8).

A recent phase III study has reported that the combination therapy of bevacizumab with FOLFOX4 (bolus and infusional 5-FU/LV plus oxaliplatin) or with XELOX (capecitabine plus oxaliplatin) significantly improves progression free survival compared with FOLFOX4 or XELOX alone in first-line metastatic colorectal cancer (9). In our present study, we evaluated the antitumor activity of bevacizumab as a monotherapy and in combination with capecitabine alone and with capecitabine and oxaliplatin in human colorectal cancer xenograft models. To understand the mechanisms of the effects of the combination of bevacizumab and capecitabine, we measured the levels of TP and VEGF, which are determinants for efficacy of capecitabine and bevacizumab, respectively.

\section{Materials and methods}

Animals. Five-week-old male BALB-nu/nu (CAnN.Cg-Foxn1 $<$ nu $>$ CrlCrlj nu/nu) mice were obtained from Charles River Laboratories Japan, Inc. (Kanagawa, Japan) and acclimatized for at least 1 week in our animal facility before use. The number of animals per experiment group was four to six, as 
specified in the figures. All animal experiments were conducted in accordance with the 'Standards for the Care and Management of Experimental Animals' and 'Rules for Animal Care and Management' promulgated in Chugai Pharmaceutical Co., Ltd.

Tumors. Three human colorectal cancer lines were used in this study. COL-16-JCK was provided by the Central Institute for Experimental Animals (Kanagawa, Japan), COLO 205 (ATCC CCL-222) was purchased from American Type Culture Collection (Manassas, VA, USA) and CXF280 was kindly provided by Dr H.H. Fiebig (University of Freiburg, Freiburg, Germany). COL-16-JCK and CXF280 were maintained in BALB-nu/nu mice by subcutaneous inoculation of tumor pieces. COLO 205 was maintained in vitro in culture medium RPMI-1640 containing $2 \mathrm{mM}$ L-glutamine, $10 \mathrm{mM}$ HEPES, $1 \mathrm{mM}$ sodium pyruvate, $4.5 \mathrm{~g} / 1$ glucose, $1.5 \mathrm{~g} / 1$ sodium bicarbonate and $10 \% \mathrm{FBS}$ at $37^{\circ} \mathrm{C}$ in an incubator with $5 \%$ $\mathrm{CO}_{2}$.

Human cancer xenograft models. Pieces $(\sim 2 \times 2 \mathrm{~mm})$ of minced tumor tissue of COL-16-JCK and CXF280 were inoculated subcutaneously (s.c.) into the right flank region of male BALB-nu/nu mice. A suspension of COLO 205 cells $\left(5 \times 10^{6}\right.$ or $8.8 \times 10^{6}$ viable cells/mouse) was injected s.c. into a male BALB-nu/nu mouse. Treatments with the antitumor drugs were started after tumors were sufficiently established in the mice. Tumor volume was estimated using the equation $\mathrm{V}=\mathrm{ab}^{2} / 2$, where $\mathrm{a}$ and $\mathrm{b}$ are tumor length and width, respectively. The percentage of tumor growth inhibition was calculated as follows: TGI\% $=[1-($ Mean change in tumor volume in each group treated with antitumor drugs/Mean change in tumor volume in the control group)] x 100 .

Immunohistochemistry. Tumor tissues were collected after treatment with bevacizumab or human IgG. Immunohistochemistry was performed using the standard method of avidin-biotin complex peroxidase staining on $4-\mu \mathrm{m}$ thick sections from paraffin-embedded, formalin-fixed tissue. The CD34 antibody (rat monoclonal antibody, clone MEC14.7; HyCult Biotechnology, Uden, The Netherlands) (10) was used to identify the microvessels.

Microvessel density (MVD). MVD was determined as the ratio of the CD34-positive area to the total observation area. Four to six fields per section $\left(0.4977 \mathrm{~mm}^{2}\right.$ each $)$ were randomly analyzed, excluding necrotic areas. The CD34-positive areas within the viable regions were measured using imaging analysis software Win ROOF (Mitani Corporation, Fukui, Japan).

TP levels in the tumor. Tumor tissues were homogenized in $10 \mathrm{mM}$ Tris-buffer (pH 7.4) containing $15 \mathrm{mM} \mathrm{NaCl}, 1.5 \mathrm{mM}$ $\mathrm{MgCl}_{2}$ and $50 \mu \mathrm{M}$ potassium phosphate buffer using a glass homogenizer. The homogenizer was then centrifuged at $10,000 \mathrm{rpm}$ for $15 \mathrm{~min}$ at $4^{\circ} \mathrm{C}$ and the supernatants were stored at $-80^{\circ} \mathrm{C}$ until use. The protein concentration of the supernatants was determined using a DC protein assay kit (Bio-Rad, Hercules, CA, USA). The level of TP was measured by ELISA with monoclonal antibodies specific to human TP, as previously described by Nishida et al (11). One unit corresponds to the amount of TP enzyme activity, which phosphorylates 5'-DFUR to 5-FU at rate of $1 \mu \mathrm{g}$ 5-FU per hour (recombinant human TP).

Levels of VEGF in tumors. Tumor tissues were homogenized in PBS buffer containing $0.05 \%$ Tween-20 using a glass homogenizer. The homogenized samples were then centrifuged at $10,000 \times \mathrm{g}$ for $20 \mathrm{~min}$ at $4^{\circ} \mathrm{C}$ and the supernatants were stored at $-80^{\circ} \mathrm{C}$ until use. The protein concentration of the supernatants was determined using a DC protein assay kit (Bio-Rad). The level of VEGF was measured using a human VEGF ELISA kit (R\&D, Minneapolis, MN, USA).

Chemicals. Bevacizumab (Avastin ${ }^{\circledR}$ ) and capecitabine $\left(\right.$ Xeloda $^{\circledR}$ ) were obtained from F. Hoffman-La Roche Ltd. (Basle, Switzerland). Oxaliplatin was kindly provided by Sanofi-Synthelabo Inc. (presently Sanofi-Aventis). Human immunoglobulin G (HuIgG) was purchased from MP Biomedicals, Inc. (Solon, OH, USA). Bevacizumab and $\mathrm{HuIgG}$ were diluted with saline and administered intraperitoneally (i.p.) twice a week for 3 weeks. Capecitabine was suspended in $40 \mathrm{mM}$ citrate buffer ( $\mathrm{pH}$ 6.0) containing $5 \%$ gum arabic as the vehicle and given orally (p.o.) for 14 days. Oxaliplatin was dissolved in $5 \%$ glucose solution and given intravenously (i.v.) once only on the day of treatment initiation.

Statistical analysis. Statistical analysis was performed using the Mann-Whitney U test. Differences were considered to be significant for values of $\mathrm{P}<0.05$.

\section{Results}

Tumor growth inhibition by bevacizumab monotherapy. We examined the antitumor activity of bevacizumab monotherapy in three human colorectal cancer xenograft models. A piece of minced COL-16-JCK tumor tissue was inoculated s.c. into the right flank region of BALB-nu/nu mice. Twenty-one days after tumor inoculation, the mice were divided into 4 groups and treatment was initiated (Day 1). Bevacizumab at doses of $1.2,2.5$ and $4.0 \mathrm{mg} / \mathrm{kg}$ and $\mathrm{HuIgG}$ at $4.0 \mathrm{mg} / \mathrm{kg}$ as the control were administered i.p. twice a week for 3 weeks. Antitumor activity was evaluated on Day 22 (21 days after the treatment was initiated). TGI\% was 46,59 and $55 \%$ in the groups treated with bevacizumab at $1.2,2.5$ and $4.0 \mathrm{mg} / \mathrm{kg}$, respectively. There were statistically significant differences in tumor volume between the control group and the groups treated with bevacizumab at doses of $1.2 \mathrm{mg} / \mathrm{kg}$ or above $(\mathrm{P}<0.05$, Fig. 1a).

BALB-nu/nu mice were injected s.c. with $5 \times 10^{6}$ cells of COLO 205 cell line into the right flank region. Nine days after the injection of the tumor cells, treatment was started. TGI\% on Day 22 was 33, 41 and $44 \%$ in the groups treated with bevacizumab at doses of $1.2,2.5$ and $4.0 \mathrm{mg} / \mathrm{kg}$, respectively. There were statistically significant differences in tumor volume between the control group and the groups treated with bevacizumab at doses of $1.2 \mathrm{mg} / \mathrm{kg}$ and above $(\mathrm{P}<0.05$, Fig. 1b).

For mice inoculated with CXF280, treatment was initiated 18 days after inoculation. TGI\% on Day 22 was 22, 40 and 
(a) COL-16-JCK

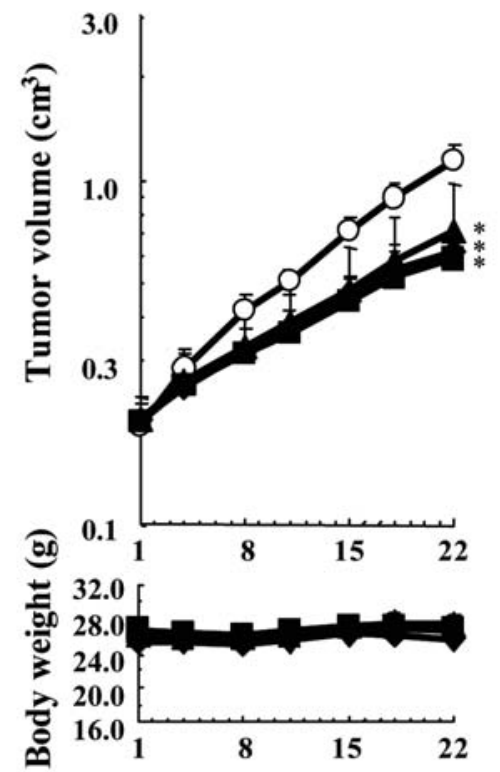

Days after start of treatment (b) COLO 205

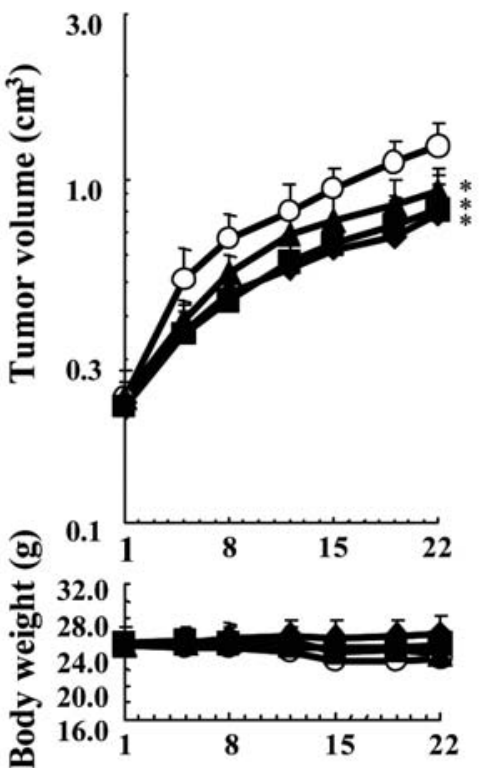

Days after start of treatment (c) CXF280

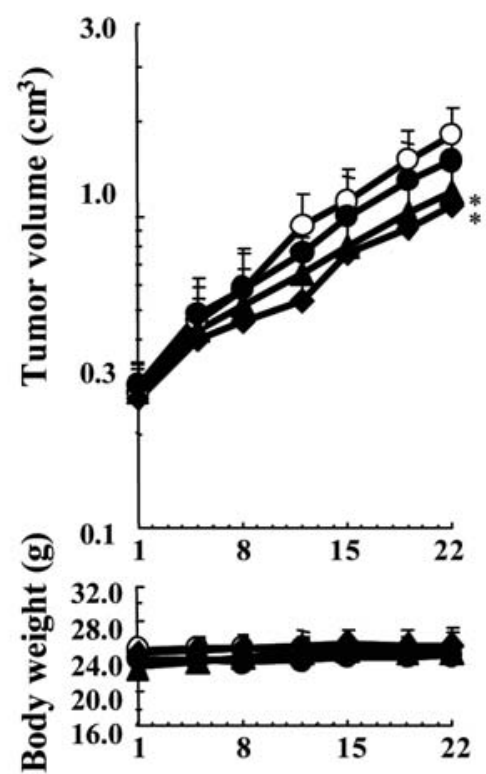

Days after start of treatment

Figure 1. Antitumor activity of bevacizumab in COL-16-JCK (a), COLO 205 (b) and CXF280 (c) human colorectal cancer xenograft models. Mice were randomly divided into 4 groups ( $\mathrm{n}=5$ or 6 /group). HuIgG or bevacizumab was administered i.p. twice a week for 3 weeks. Data points indicate mean values $\pm \mathrm{SD}$ of tumor volume or body weight. $\bigcirc$, HuIgG $4.0 \mathrm{mg} / \mathrm{kg}$ (control group); $\bullet$, bevacizumab $0.4 \mathrm{mg} / \mathrm{kg}$; $\boldsymbol{\Delta}$, bevacizumab $1.2 \mathrm{mg} / \mathrm{kg}$; $\mathbf{0}$, bevacizumab $2.5 \mathrm{mg} / \mathrm{kg}$; -, bevacizumab $4.0 \mathrm{mg} / \mathrm{kg}$. $\mathrm{P}<0.05$ vs. control group.

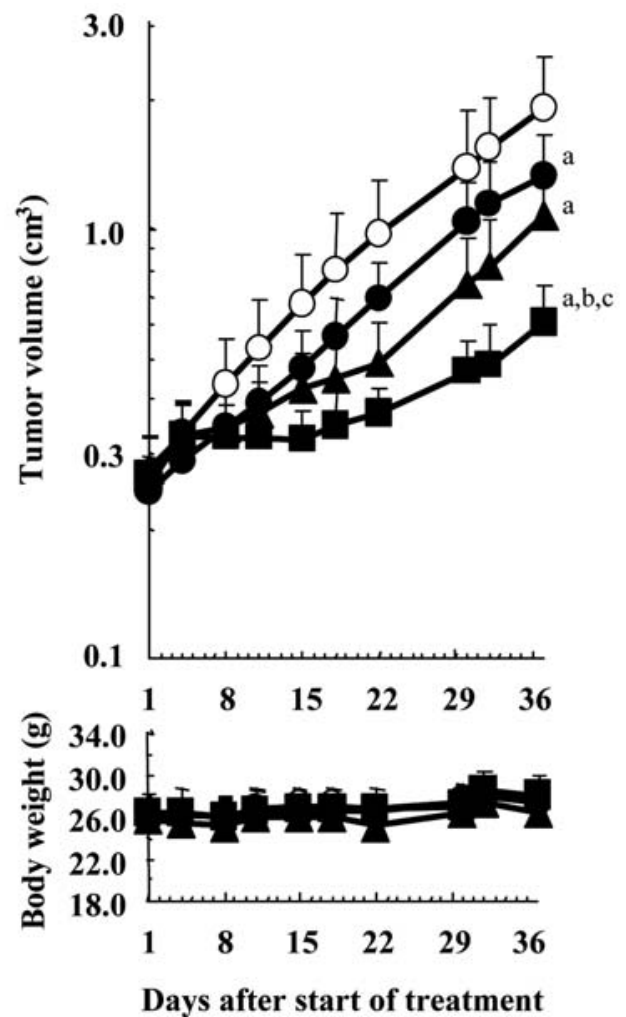

Figure 2. Antitumor activity of bevacizumab in combination with capecitabine in COL-16-JCK human colorectal cancer xenograft models. HuIgG or bevacizumab was administered i.p. twice a week for 3 weeks and capecitabine was given p.o. daily for 14 days. Data points indicate mean values \pm SD of tumor volume or body weight $(\mathrm{n}=6) . \odot$, HuIgG $4 \mathrm{mg} / \mathrm{kg}$ (control group); bevacizumab $4 \mathrm{mg} / \mathrm{kg}$; $\boldsymbol{\Delta}$, capecitabine $359 \mathrm{mg} / \mathrm{kg}$; $\mathbf{\square}$, capecitabine $359 \mathrm{mg} / \mathrm{kg}$ and bevacizumab $4 \mathrm{mg} / \mathrm{kg}$. ${ }^{\mathrm{a}} \mathrm{P}<0.05 \mathrm{vs}$. control group; ${ }^{\mathrm{b}} \mathrm{P}<0.05$ vs. capecitabine group; ${ }^{\mathrm{c}} \mathrm{P}<0.05$ vs. bevacizumab group.
$47 \%$ in the groups treated with bevacizumab at doses of 0.4 , 1.2 and $4.0 \mathrm{mg} / \mathrm{kg}$, respectively. There were statistically significant differences in tumor volume between the control group and the groups treated with bevacizumab at doses of $1.2 \mathrm{mg} / \mathrm{kg}$ and above $(\mathrm{P}<0.05$, Fig. 1c).

No significant decrease in body weight was observed in any of the groups of the three xenograft models (Fig. 1a, b and c).

Antitumor activity of bevacizumab in combination with capecitabine. We evaluated the antitumor activity of bevacizumab in combination with capecitabine in two human colorectal cancer xenograft models. Twenty-seven days after inoculation with COL-16-JCK tumors, the mice were divided into 4 groups (6 mice per group) and treatment was initiated (Day 1). Bevacizumab was administered i.p. at $4 \mathrm{mg} / \mathrm{kg}$ twice a week for 3 weeks and capecitabine was orally administered at $359 \mathrm{mg} / \mathrm{kg}$ [2/3 maximum tolerated dose (MTD)] (8) daily for 14 days. On Day 37, there were statistically significant differences in tumor volume between the control and the groups treated with capecitabine, bevacizumab and bevacizumab in combination with capecitabine. There were also statistically significant differences in tumor volume between the group treated with bevacizumab in combination with capecitabine and the groups treated with bevacizumab and capecitabine alone (P<0.05, Fig. 2). TGI\% on Day 37 was $52 \%$ in the capecitabine group, $35 \%$ in the bevacizumab group and $80 \%$ in the capecitabine + bevacizumab combination group.

COLO 205 colorectal cancer cells $\left(8.8 \times 10^{6}\right)$ were injected s.c. into the right flank region of BALB-nu/nu mice. Seven days after tumor cell injection, the mice were divided into 


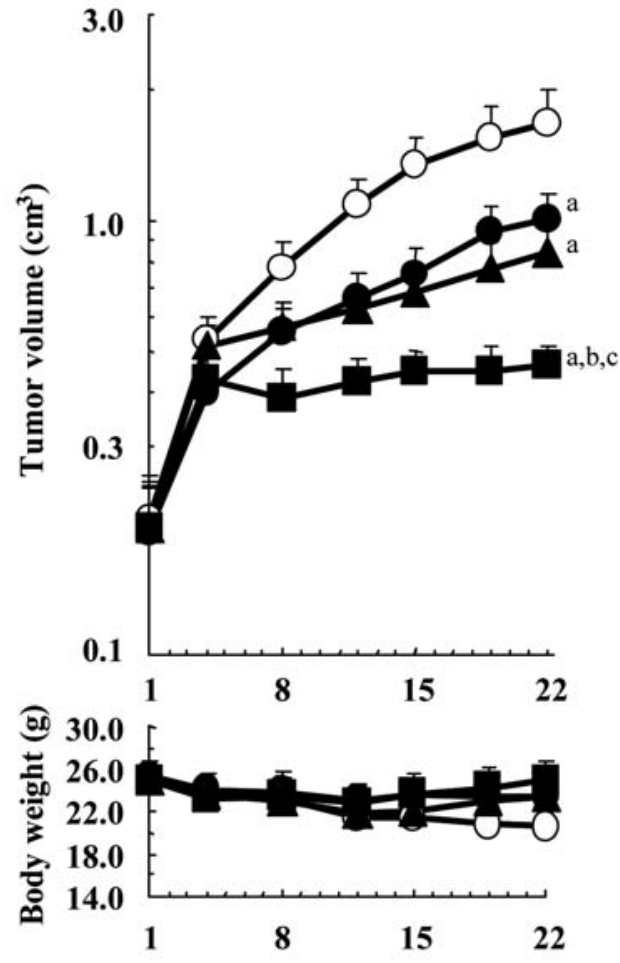

Days after start of treatment

Figure 3. Antitumor activity of bevacizumab in combination with capecitabine in COLO 205 human colorectal cancer xenograft models. HuIgG or bevacizumab was administered i.p. twice a week for 3 weeks and capecitabine was given p.o. daily for 14 days. Data points indicate mean values $\pm \mathrm{SD}$ of tumor volume or body weight ( $\mathrm{n}=6)$. $\odot, \mathrm{HuIgG} 4 \mathrm{mg} / \mathrm{kg}$ (control group); $\bullet$, bevacizumab $4 \mathrm{mg} / \mathrm{kg}$; $\boldsymbol{\Lambda}$, capecitabine $269 \mathrm{mg} / \mathrm{kg}$; $\mathbf{\square}$, capecitabine $269 \mathrm{mg} / \mathrm{kg}$ and bevacizumab $4 \mathrm{mg} / \mathrm{kg}$. ${ }^{\mathrm{P}} \mathrm{P}<0.05$ vs. control group; ${ }^{\mathrm{b}} \mathrm{P}<0.05$ vs. capecitabine group; ${ }^{\mathrm{C}} \mathrm{P}<0.05$ vs. bevacizumab group.

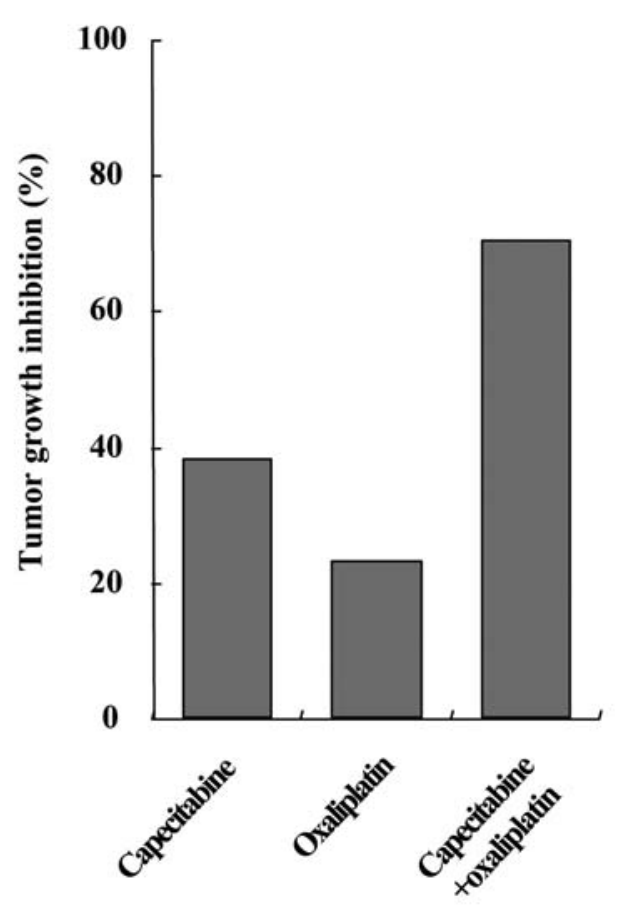

Figure 4. Tumor growth inhibition (\%) of capecitabine + oxaliplatin in COL-16-JCK. Mice were randomly divided into groups $(n=6)$. Capecitabine $(180 \mathrm{mg} / \mathrm{kg}$ ) was administered p.o. once a day for 14 days. Five $\mathrm{mg} / \mathrm{kg}$ of oxaliplatin was administered i.v. on Day 1. TGI\% was evaluated on Day 36.

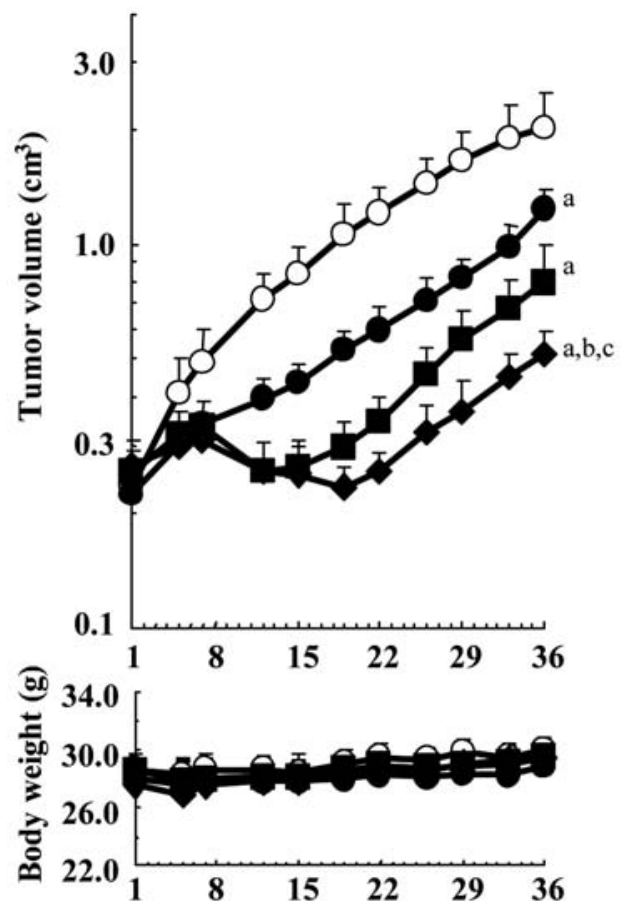

Days after start of treatment

Figure 5. Antitumor activity of bevacizumab in combination with capecitabine + oxaliplatin in COL-16-JCK. HuIgG or bevacizumab was administered i.p. twice a week for 3 weeks and capecitabine was given p.o. daily for 14 days. Oxaliplatin was administered i.v. on Day 1. Data points indicate mean values $\pm \mathrm{SD}$ of tumor volume or body weight $(\mathrm{n}=6) . \mathrm{O}, \mathrm{HuIgG}$ $4 \mathrm{mg} / \mathrm{kg}$ (control group); $\bullet$, bevacizumab $4 \mathrm{mg} / \mathrm{kg}$;, capecitabine $180 \mathrm{mg} / \mathrm{kg}$ and oxaliplatin $5 \mathrm{mg} / \mathrm{kg}$ (cape + oxali group); , capecitabine $180 \mathrm{mg} / \mathrm{kg}$, oxaliplatin $5 \mathrm{mg} / \mathrm{kg}$, and bevacizumab $4 \mathrm{mg} / \mathrm{kg}$. aP $<0.05$ vs. control group; ${ }^{\mathrm{b}} \mathrm{P}<0.05$ vs. cape + oxali group; ${ }^{\mathrm{c}} \mathrm{P}<0.05$ vs. bevacizumab group.

4 groups (6 mice per group) and treatment was initiated (Day 1). Bevacizumab was administered i.p. at $4 \mathrm{mg} / \mathrm{kg}$ twice a week for 3 weeks. Capecitabine was administered p.o. at $269 \mathrm{mg} / \mathrm{kg}$ [1/2 MTD (8)] daily for 14 days. Tumor volumes on Day 22 were significantly smaller in the capecitabine + bevacizumab group than in groups treated with each agent alone $(\mathrm{P}<0.05$, Fig. 3$)$. TGI\% was $55 \%$ in the capecitabine group, $44 \%$ in the bevacizumab group and $82 \%$ in the capecitabine + bevacizumab combination group.

No significant difference in body weight was observed between mice treated with capecitabine + bevacizumab and those treated with each single agent in the COL-16-JCK and COLO 205 models (Figs. 2 and 3).

Antitumor activity of bevacizumab in combination with capecitabine + oxaliplatin. The mice inoculated with COL16-JCK were divided into 6 groups (6 mice per group); 25 days after tumor inoculation treatments were initiated (Day 1). Capecitabine was administered p.o. at $180 \mathrm{mg} / \mathrm{kg}$ (1/3 MTD) (8) daily for 14 days. Oxaliplatin was administered i.v. at $5 \mathrm{mg} / \mathrm{kg}$ (1/3 MTD) (12) on Day 1 and $4 \mathrm{mg} / \mathrm{kg}$ of bevacizumab was administered i.p. twice a week for 3 weeks. On Day 36 , bevacizumab and capecitabine significantly inhibited tumor growth as single agent. TGI\% was $38 \%$ in the capecitabine group, $23 \%$ in the oxaliplatin group and $70 \%$ in the capecitabine + oxaliplatin group (Fig. 4). Capecitabine in 
Table I. Levels of TP from treatment with bevacizumab and VEGF from treatment with capecitabine in COL-16-JCK and COLO 205 xenografts. ${ }^{\mathrm{a}}$

\begin{tabular}{lccrc}
\hline & \multicolumn{2}{c}{ TP level (U/mg protein) } & \multicolumn{2}{c}{ VEGF level (pg/mg protein) } \\
\cline { 2 - 5 } Cell line & HuIgG $(4 \mathrm{mg} / \mathrm{kg})$ & Bevacizumab $(4 \mathrm{mg} / \mathrm{kg})$ & Vehicle & Capecitabine $(539 \mathrm{mg} / \mathrm{kg})$ \\
\hline COL-16-JCK & $2.1 \pm 0.7$ & $2.7 \pm 5.8$ & $281.2 \pm 36.0$ & $272.0 \pm 21.3$ \\
COLO 205 & $8.5 \pm 0.6$ & $9.5 \pm 2.4$ & $\mathrm{NT}$ & NT \\
\hline
\end{tabular}

${ }^{a} \mathrm{HuIgG}$ or bevacizumab was administered i.p. twice a week for 3 weeks. Capecitabine was given p.o. daily for 13 days. The levels of TP and VEGF in tumor tissue were measured by ELISA. NT, not tested.
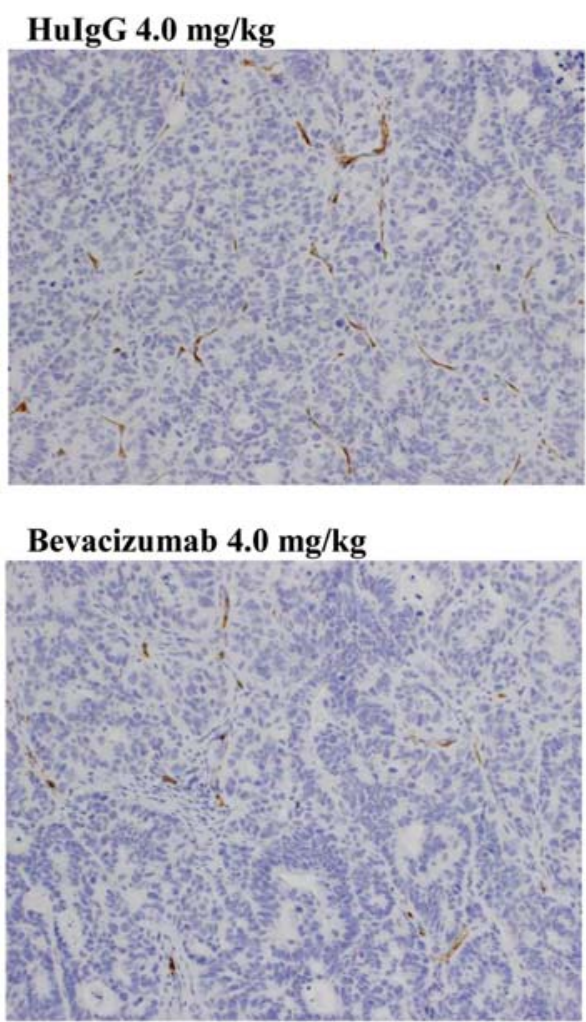

Figure 6. Images of CD34 staining for MVD in COL-16-JCK. Mice were randomly assorted into groups $(n=4)$. HuIgG or bevacizumab was administered i.p. twice a week for 3 weeks. Tumor tissues were collected on Day 23 (5 days after the last treatment) and MVD was evaluated. Immunohistochemical staining for CD34 using the avidin-biotin-peroxidase complex method was performed on $4-\mu \mathrm{m}$ thick sections of paraffin-embedded formalin-fixed tissue.

combination with oxaliplatin showed significantly higher antitumor activity than capecitabine, although oxaliplatin as a single agent showed no significant antitumor activity.

Furthermore, the antitumor activity of bevacizumab in combination with capecitabine + oxaliplatin (TGI: $86 \%$ ) was significantly superior to that of capecitabine + oxaliplatin (TGI: 70\%) and that of bevacizumab alone (TGI: 44\%). No significant difference in body weight was observed between mice treated with capecitabine + oxaliplatin alone and those treated with capecitabine + oxaliplatin + bevacizumab (Fig. 5).

Effect of bevacizumab on MVD. We investigated the effect of bevacizumab on microvessel density (MVD) in tumor tissues of the COL-16-JCK xenograft model by using

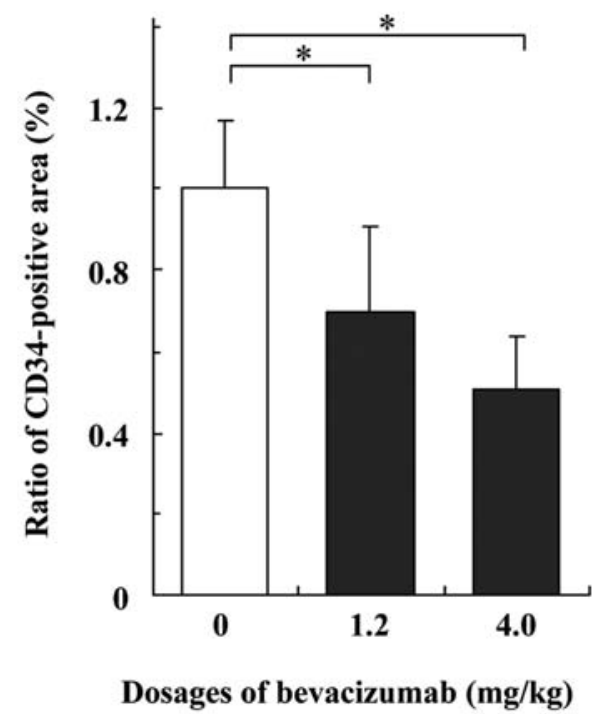

Figure 7. Effect of bevacizumab on MVD. HuIgG or bevacizumab was administered i.p. twice a week for 3 weeks. MVD was determined by the ratio of the CD34-positive area to the total observation area using imaging analysis software, Win ROOF. ${ }^{*} \mathrm{P}<0.05(\mathrm{n}=4)$.

immunohistochemical staining for CD34. Bevacizumab at doses of 1.2 and $4.0 \mathrm{mg} / \mathrm{kg}$ and $\mathrm{HuIgG}$ at $4.0 \mathrm{mg} / \mathrm{kg}$ as a control were administered i.p. twice a week for 3 weeks (41 days post-tumor inoculation). Tumor tissues were collected 5 days after the last treatment (Day 23). TGI\% was, respectively, 43 and $45 \%$ in the groups treated with bevacizumab at 1.2 and $4.0 \mathrm{mg} / \mathrm{kg}$ on Day 23. Typical immunohistochemical staining images of CD34 are shown in Fig. 6. The MVD was determined as the ratio of the CD34positive area to the total observation area and were $1.00,0.70$ and $0.51 \%$ at the dosages of 0 (control), 1.2 , and $4.0 \mathrm{mg} / \mathrm{kg}$ of bevacizumab, respectively; MVD values were significantly lower for the bevacizumab-treated groups than for the control group $(\mathrm{P}<0.05$, Fig. 7$)$.

Levels of TP and VEGF in tumor tissues. We measured the levels of TP and human VEGF in tumor tissues in COL-16JCK and COLO 205 xenograft models. Levels of tumor TP were not changed after i.p. administration of bevacizumab at $4 \mathrm{mg} / \mathrm{kg}$ twice a week for 3 weeks in the COL-16-JCK and COLO 205 xenograft models. The level of VEGF in tumor was not increased by capecitabine treatment $(539 \mathrm{mg} / \mathrm{kg}$, daily for 13 days) in the COL-16-JCK model (Table I). 


\section{Discussion}

In our present study, we demonstrated the antitumor activity of bevacizumab as a monotherapy and in combination therapies with capecitabine and capecitabine + oxaliplatin in human colorectal cancer xenograft models. The antitumor activity of bevacizumab in combination with capecitabine was significantly higher than that of bevacizumab monotherapy in 2 xenograft models. In addition, we investigated the mechanisms of the combination effects of bevacizumab and capecitabine in the 2 xenograft models.

Capecitabine is enzymatically metabolized to 5-FU as a result of the highly expressed TP in the tumor. It has been reported that the antitumor activity of capecitabine correlates with tumor levels of TP activity in xenograft models (8). Some chemotherapeutic drugs, such as the taxanes, have been reported to increase the levels of TP in tumors in xenograft models and to show significantly more potent antitumor activity in combination with capecitabine than each agent as a monotherapy (12-14). It has been also reported that oxaliplatin treatment increased the level of TP in tumor tissues in xenograft models (15). In the present study, we investigated the levels of TP in tumors after treatment with bevacizumab to evaluate possible therapeutic effects in combination with capecitabine and with capecitabine + oxaliplatin in xenograft models. However, bevacizumab induced no significant increase in levels of TP in the 2 xenograft models used, suggesting that the combination effects are a result of mechanisms other than TP up-regulation in tumors treated with bevacizumab. A4.6.1 has been reported to increase pO2 in tumor tissues (16). On the other hand, hypoxia has been reported to induce TP in tumor cells (17) and might explain the lack of an increase in the levels of TP in the tumor after treatment with bevacizumab in the xenograft models tested.

Bevacizumab binds to human VEGF and inhibits its biological activities. VEGF has been reported to be expressed in tumor tissues and to play a major role in tumor angiogenesis (18-21). As in many studies, the present study also demonstrated that bevacizumab decreased microvessel density in the tumor tissues of the xenograft models. In tumors expressing VEGF, tumor growth would be more dependent on angiogenesis regulated by VEGF. Therefore, we investigated the level of VEGF after treatment with capecitabine to possibly explain the mechanisms of the effects of bevacizumab and capecitabine in combination. However, no significant increase in tumor VEGF was demonstrated after treatment with capecitabine, suggesting that the combination effects are a result of mechanisms other than change in the level of VEGF in tumors treated with capecitabine.

In the present study using human colorectal cancer xenograft models, we investigated the possible mechanisms explaining the clinical benefits demonstrated in a phase III study of combination therapy of bevacizumab with XELOX in colorectal cancer patients. The levels of TP and VEGF measured in tumor, however, did not explain the mechanism of the effects of the combination demonstrated in xenograft models. Previously, A4.6.1 has been shown to increase the concentration of anticancer agents in the tumor tissues as compared with anticancer agents alone (22). We will further investigate the mechanisms of combination therapies plus bevacizumab in xenograft models that show effects of antitumor activity.

\section{Acknowledgements}

We thank Sanofi Synthelabo (presently Sanofi-Aventis) for providing oxaliplatin, Dr H.H. Fiebig of Freiburg University, Germany for providing the CXF280 cell line and Ms. F. Ford for English language proofreading.

\section{References}

1. Presta LG, Chen H, O'Connor SJ, Chisholm V, Meng YG, Krummem L, Winkler M and Ferrara N: Humanization of an anti-vascular endothelial growth factor monoclonal antibody for the therapy of solid tumors and other disorders. Cancer Res 57: 4593-4599, 1997.

2. Kim KJ, Li B, Houck K, Winner J and Ferrara N: The vascular endothelial growth factor proteins: identification of biologically relevant regions by neutralizing monoclonal antibodies. Growth Factors 7: 53-64, 1992.

3. Wang Y, Fei D, Vanderlaan M and Song A: Biological activity of bevacizumab, a humanized anti-VEGF antibody in vitro. Angiogenesis 7: 335-345, 2004.

4. Kim KJ, Li B, Winer J, Armanini M, Gillett N, Phillips HS and Ferrara N: Inhibition of vascular endothelial growth factorinduced angiogenesis suppresses tumor growth in vivo. Nature 362: 841-844, 1993.

5. Gerber H-P and Ferrara N: Pharmacology and pharmacodynamics of Bevacizumab as monotherapy or in combination with cytotoxic therapy in preclinical studies. Cancer Res 65: 671-680, 2005.

6. Hurwitz H, Fehrenbacher L, Novotny W, Cartwright T, Hainsworth J, Heim W, Berlin J, Baron A, Griffing S, Holmgren E, Ferrara N, Fyfe G, Rogers B, Ross R and Kabbinavar F: Bevacizumab plus irinotecan, fluorouracil, and leucovorin for metastatic colorectal cancer. N Engl J Med 350 : 2335-2342, 2004.

7. Kabbinavar F, Hurwitz HI, Fehrenbacher L, Meropol NJ, Novotny WF, Lieberman G, Griffing S and Bergsland E: Phase II, randomized trial comparing bevacizumab plus fluorouracil (FU)/leucovorin (LV) with FU/LV alone in patients with metastatic colorectal cancer. J Clin Oncol 21: 60-65, 2003.

8. Ishikawa T, Sekiguchi F, Fukase Y, Sawada N and Ishituka H: Positive correlation between the efficacy of capecitabine and doxifluridine and the ratio of thymidine phosphorylase to dihydropyrimidine dehydrogenase activities in tumors in human cancer xenografts. Cancer Res 58: 685-690, 1998.

9. Saltz LB, Clarke S, Díaz-Rubio E, Scheithauer W, Figer A, Wong R, Koski S, Lichinister M, Yang Tsai-Shen, Rivera F, Couture F, Sirzen F and Cassidy J: Bevacizumab in combination with oxaliplatin-based chemotherapy as first-line therapy in metastatic colorectal cancer: a randomized phase III study. J Clin Oncol 26: 2013-2019, 2008.

10. Garlanda C, Berthier R, Garin J, Stoppacciaro A, Ruco L, Vittet D, Gulino D, Matteucci C, Mantovani A, Vecchi A and Dejana E: Characterization of MEC 14.7, a new monoclonal antibody recognizing mouse CD34: a useful reagent for identifying and characterizing blood vessels and hematopoietic precursors. Eur J Cell Biol 73: 368-377, 1997.

11. Nishida M, Hino A, Mori K. Matsumoto T, Yoshikubo T and Ishitsuka H: Preparation of anti-human thymidine phosphorylase monoclonal antibodies useful for detecting the enzyme levels in tumor tissues. Biol Pharm Bull 19: 1407-1411, 1996.

12. Sawada N, Ishikawa T, Fukase Y, Nishida M, Yoshikubo T and Ishituka H: Induction of thymidine phosphorylase activity and enhancement of capecitabine efficacy by Taxol/Taxotere in human cancer xenografts. Clin Cancer Res 4: 1013-1019, 1998.

13. Endo M, Shinbori N, Hukase Y, Sawada N, Ishikawa T, Ishitsuka $\mathrm{T}$ and Tanaka Y: Induction of thymidine phosphorylase expression and enhancement of efficacy of capecitabine or 5'deoxy-fluorouridine by cyclophosphamide in mammary tumor models. Int J Cancer 83: 127-134, 1999.

14. Ishituka H, Ishikawa T, Fukase Y, Sawada N, Tanaka Y, Ouchi K, Yoshikubo T and Nishida M: Capecitabine and the dThdPase upregulators IFN $\gamma$ or Taxol showed synergistic activity in human cancer xenografts. Proc Am Assoc Cancer Res 37: 2766, 1996. 
15. Sawada N, Kondoh K and Mori K: Enhancement of capecitabine efficacy by oxaliplatin in human colorectal and gastric cancer xenografts. Oncol Rep 18: 775-778, 2007.

16. Lee CG, Heijin M, di Tomaso E, Griffon-Etienne G, Ancukiewicz M, Koike C, Park KR, Ferrara N, Jain RK, Suit HD and Boucher Y: Anti-vascular endothelial growth factor treatment augments tumor radiation response under normoxic or hypoxic conditions. Cancer Res 60: 5565-5570, 2000.

17. Akiyama S, Hurukawa T, Sumizawa T, Takebayashi Y, Nakajima Y, Shimaoka S and Haraguchi M: The role of thymidine phosphorylase, an angiogenic enzyme, in tumor progression. Cancer Sci 95: 851-857, 2004.

18. Ferrara N and Henzwl WJ: Pituitary follicular cells secrete a novel heparin-binding growth factor specific for vascular endotherial cells. Biochem Biophys Res Commun 161: 851-858, 1989.
19. Leung DW, Cachianes G, Kuang W-J, Goeddel DV and Ferrara N: Vascular endothelial growth factor is a secreted angiogenic mitogen. Science 246: 1306-1309, 1989.

20. Ferrara N: Vascular endothelial growth factor as a target for anticancer therapy. Oncologist 9: 2-10, 2004.

21. Ferrara N, Hillan KJ and Novotny W: Bevacizumab (Avastin), a humanaized anti-VEGF monoclonal antibody for cancer therapy. Biochem Biophys Res Commun 333: 328-335, 2005.

22. Wilders H, Guetens G, Boeck GD, Verbeken E, Landuyt B, Landuyt W, de Bruijin EA and van Oosterom AT: Effect of antivascular endotherial growth factor treatment on the intratumoral uptake of CPT-11. Br J Cancer 88: 1979-1986, 2003. 